\title{
Retraction Note: Mountain atmospheric characteristics based on 5G big data and Yunnan minority pattern design
}

\author{
Yuanyuan $\mathbf{L i}^{1}$
}

Published online: 4 November 2021

C) Saudi Society for Geosciences 2021

Retraction Note to:: Arabian Journal of Geosciences (2021) 14: 1761 https://doi.org/10.1007/s12517-021-07904-8

The Editor-in-Chief and the Publisher have retracted this article because the content of this article is nonsensical. The peer review process was not carried out in accordance with the Publisher's peer review policy. The author does not agree to this retraction.

The original article can be found online at https://doi.org/10.1007/ s12517-021-07904-8.

Yuanyuan Li

sunyuqiu0311@163.com

1 College of Art and Design, Yunnan Technology and Business University, Kunming 651700, Yunnan, China 